\title{
WITH ALL OUR GROWTH, SADLY, BULLYING CONTINUES IN EVERY ASPECT OF NURSING
}

\author{
Lorna Kendrick
}

\author{
SAS Doctoral Program Adjunct Faculty, \\ Research Fellow at UOPX Center for Health Engineering Research \\ Professor of Nursing at California Baptist University, USA
}

These are exciting times of growth for the profession of nursing, where the opportunities are endless and especially motivating and exhilarating for schools of nursing. Although nursing educators are rising to the occasion and changing curricula to keep up with all the shifting and growth within our profession, we still struggle with one major issue. The issue of bullying in nursing or "eating our own" as it has been called in our recent nursing past is alive and threaded through the fabric of our profession like a virus.

Bullying, as a societal issue, has recently received national attention. We often read heart wrenching stories about everyday people whose lives have been shattered as a result of bullying. Although bullying is not a new phenomenon the realization of its affect is forcing us as a society to call for an end to this behavior towards others. According to Merriam-Webster.com bullying is defined as, "a blustering browbeating person; one habitually cruel to others who are weaker." Unlike classic intentional bullying noted through the years, professional bullying in nursing tends to happen unbeknownst to the perpetrator.

Some have hypothesized that nurse on nurse maltreatment is prevalent because historically, as a profession of mainly women, nurses were often at the receiving end of a cast-like system where they were often blamed by irate doctors and others who themselves were stressed and frustrated. So in turn, nurses would mistreat their own nursing colleagues because they observed this method to be an acceptable way to gain power and generate a desired response from another. Hence, bullying among nurses is likely a result of the "victim turned perpetrator" stemming from theories such as Social Learning theory (Bandura, 1977) and/or Operant/Classical Conditioning (Skinner, 1953; Pavlov, 2003).

Often when nurses do share their feelings with colleagues about experiences with bullying there is empathy, concern, support and the sharing of similar experiences. Yet, when a nurse is courageous enough to confront a bullying colleague, often rather than acknowledging the occurrence, denial is the behavior of choice. If there is some semblance of awareness or acknowledgement justification frequently accompanies the admittance. Several nurses shared the following as responses to their reporting of bullying, "We would never allow bullying here" or "Are you sure, I'm sure that wasn't the intent", or "You can't worry about it, that person does it all the time, we just ignore or avoid him/her".

All nurses acknowledge the problem of bullying, yet few believe they are guilty of the behavior. As a colleague once shared, "Most nurses don't realize they are eating another until the victim's screams, while being chewed, are heard coming from inside their mouth." Sadly, most have become so accustomed to this treatment they no longer scream in recognition. Instead they suffer in silence.

In response to a number of factors over the years (i.e., retention, satisfaction, costs, etc) related to bullying in health care settings in particular, have attempted to end bullying through mandatory trainings focused on civility with the intent being zero tolerance. Yet, bullying continues. Numerous stories of bullying from nursing students, academician, administrators and nursing clinician alike have been shared with this writer. The stories range from comments such as, "this is a nursing lounge and you are a student so LEAVE", to new faculty being totally ignored by other faculty and/or leaders and senior nursing researchers yelling at and demeaning junior faculty researchers (Hutchinson et al., 2006).

Sadly, bullying impacts not only the retention of nurses in hospitals and other settings as noted in the literature (Seibel, 2013) but bullying influences the 
future direction and choices of students pursuing a nursing degree (Randle, 2003). Many nursing students are already seeking alternate nursing roles upon graduation in an attempt to avoid the bullying they witness both in their clinical training experiences and in their classes (i.e., overwhelming number of assignments, being told if you want to be successful you will stop working, nursing is difficult I am not sure you should apply, your grades from 20 years ago tell me you aren't serious about school, being dismissed because faculty disagree with life choices, $16 \mathrm{~h}$ class days followed by $12 \mathrm{~h}$ clinical days, etc).

Although nursing education is evolving to address innovations within health care, it has not been successful in eradicating nurse to nurse maltreatment (bullying). Many nurses move into academic roles hoping to leave bullying behind, thinking more seasoned and educated nurses no longer experience or allow bullying. These new nursing academics find, surprisingly, that bullying is alive and well but more sophisticated and ambiguous. Academician report examples such as punishment by being assigned courses no one else wants to teach, being removed from committees, showing favoritism, being told in meetings if you're not happy there are lots of jobs elsewhere, being defamed in meetings and academic leaders sharing personal information in public meetings with the intent to so upset and anger a faculty member where he/she will just walk away.

Is there a solution? Is it possible to change the landscape? Where do we begin? One solution is to begin to compile a list of bullying behaviors (France and Hardin, 2012). It is difficult to identify a behavior if we are not familiar with what it actually looks like or how it manifests itself. For example, words like yelling, demeaning, power, maltreatment and mistreated have already been mentioned. The only word used here that gives a clear picture of what bullying looks like is yelling. The other words are so esoteric in meaning it would be difficult for most to easily associate their behaviors with these words. For example what does demeaning behavior actually look like and/or how does it manifest during human encounters? A colleague gave the following example for demeaning behavior, "Confronting a colleague in front of another person, blaming them for a mistake and/or rolling one's eyes when someone is talking are all simple examples of demeaning." These behaviors have occurred at all levels of nursing relationships from nurse to nurse, nurse administrator to nurse, charge nurse to nurse, nursing dean to nursing faculty, nursing faculty to nursing student, nursing faculty mentor to junior nursing faculty mentee and so on.
Sadly, human nature's desire is to save face. Here is where the solutions fail. What if instead of saving face you catch yourself in the midst of bullying and you stop and say, "Oh dear, I just realized I was not being kind, I am so sorry, let's start over." If each person were to make an individual commitment and effort to try this, the rippling effect would be seen and heard around the world. The profession of nursing would succeed in modeling for the world a solution that would truly make a difference.

Therefore, this editorial challenges every colleague reading these words to, as we say in our earthquake preparedness training, "stop, drop and roll." STOP as soon as you realize your words, decisions, actions, or behaviors are bullying/maltreatment, DROP your pride and need to save face and ROLL your kindness over the bullying to destroy it. You might be saying this seems just too simple and childlike; but we also realize all of the evidence based solutions have not stopped bullying. However, when we watch the behaviors of children at play, where bullying isn't present, we see friendships nurtured that often continue for a life-time. Will you take the challenge so we can go from "yet, bullying continues" to "Breaking News, Nursing has eradicated bullying within their profession, let's follow their lead?"

\section{REFERENCES}

Bandura, A., 1977. Social learning theory. New York: General Learning Press.

France, N. and S. Hardin, 2012. Caring praxis in nursing education: Breaking the cycle of 'nurses eating their own. Int. J. Human Caring, 16: 63-4.

Hutchinson, M., M. Vickers, D. Jackson and L. Wilkes, 2006. Workplace bullying in nursing: Towards a more critical organisational perspective. Nurs. Inquiry, 13: 118-126. PMID: 16700755

Pavlov, I.P., 2003. Conditioned Reflexes. 1st Edn., Courier Dover Publications, ISBN-10: 0486430936 , pp: 430.

Randle, J., 2003. Bullying in the nursing profession. J. Adv. Nurs., 43: 395-401. PMID: 12887358

Seibel, M., 2013. For us or against us? Perceptions of faculty bullying of students during undergraduate nursing education clinical experiences. Nurse Edu. Practice, 14: 271-4. DOI: 10.1016/j.nepr.2013.08.013

Skinner, B.F., 1953. Science and Human Behavior. 1st Edn., reprint, Simon and Schuster, ISBN-10: 0029290406, pp: 461. 